\title{
A pilot randomized-controlled trial evaluating the erector spinae plane block in thoracic and breast surgery
}

\author{
Yoshiaki Uda, MBBS FANZCA (D) - Kelly Byrne, MBChB FANZCA - Anjalee Brahmbhatt, MBChB FRCA \\ FANZCA AFRACMA - Robert Gotmaker, MBBS FANZCA MBiostat - Daniel Lim, M PharmPrac • \\ Yasutaka Konishi, MD DrPH $\cdot$ Tessa Katherine Eves, BSc (Hons) $\cdot$ Emma Paxton, MD • \\ Michael J. Barrington, FANZCA PhD
}

Received: 20 January 2020/Revised: 12 May 2020/ Accepted: 13 May 2020/Published online: 21 July 2020

(C) Canadian Anesthesiologists' Society 2020

\begin{abstract}
Purpose This pilot study evaluated the feasibility of investigating the effect of the erector spinae plane (ESP) block on the patient-centred outcomes of quality of recovery-15 (QoR-15), and brief pain inventory (BPI) in thoracic and breast surgery patients.

Methods In this randomized-controlled pilot trial, 82 patients undergoing video-assisted thoracoscopic surgery $(n=77)$ and mastectomy $(n=5)$ received either continuous ESP block with ropivacaine (ropivacaine group) or the same procedure with $0.9 \%$ saline (saline group). All patients received surgical intercostal block (thoracic surgery) or local anesthetic infiltration (breast surgery). Feasibility as the primary outcome was evaluated on recruitment (three patients per week), catheter retention (above $90 \%$ at $24 \mathrm{hr}$ ), and patient attrition (less than 10\%). Secondary outcomes comprised of QoR-15, BPI, and opioid consumption.
\end{abstract}

Y. Uda, MBBS FANZCA $(\bowtie) \cdot$ R. Gotmaker, MBBS FANZCA MBiostat $\cdot$ E. Paxton, MD

Department of Anaesthesia and Acute Pain Medicine, St.

Vincent's Hospital, Victoria Parade, Fitzroy, PO Box 2900,

Melbourne, VIC 3065, Australia

e-mail: Yoshiaki.Uda@svha.org.au

K. Byrne, MBChB FANZCA

Department of Anaesthesia, Waikato Hospital, Hamilton, New Zealand

A. Brahmbhatt, MBChB FRCA FANZCA AFRACMA .

M. J. Barrington, FANZCA PhD

Department of Anaesthesia and Acute Pain Medicine, St.

Vincent's Hospital, Victoria Parade, Fitzroy, PO Box 2900,

Melbourne, VIC 3065, Australia

Department of Medicine and Radiology, Faculty of Medicine, Dentistry and Health Sciences, University of Melbourne,

Melbourne, VIC, Australia
Results Recruitment rate was 1.8 patients per week. Catheters were retained in 77 patients (94\%) at $24 \mathrm{hr}$. At three months, five patients were lost to follow-up (6\%). At $24 \mathrm{hr}$ compared with baseline, the ropivacaine group had a smaller decline in QoR-15 score (median difference, 14; 95\% confidence interval [CI], 2 to $26 ; P=0.02$ ) and a smaller increase in BPI global score (median difference, 14; 95\% CI, 0 to 24; $P=0.048)$. There was no difference in opioid consumption $(P=0.08)$.

Conclusions In this pilot study, the target recruitment rate was not met, but catheter retention and patient attrition rates were both satisfactory. A definitive trial with QoR-15 as the primary outcome would require 300 study participants.

Trial registration Australian New Zealand Clinical Trials Registry (ID12618000701224); registered 30 April 2018.

D. Lim, M PharmPrac

Department of Pharmacy, St. Vincent's Hospital, Melbourne, VIC, Australia

Y. Konishi, MD DrPH

Department of Anaesthesia and Acute Pain Medicine, St. Vincent's Hospital, Victoria Parade, Fitzroy, PO Box 2900, Melbourne, VIC 3065, Australia

Department of Anesthesia, School of Medicine, Teikyo University, Tokyo, Japan

T. K. Eves, BSc (Hons)

Department of Anatomy and Neuroscience, Faculty of Medicine, Dentistry and Health Sciences, University of Melbourne, Melbourne, VIC, Australia 


\section{Résumé}

Objectif Cette étude pilote a évalué la faisabilité d'explorer l'effet d'un bloc du plan des muscles érecteurs du rachis sur des résultats centrés sur le patient, soit la qualité de récupération (QoR-15) et le Questionnaire concis de la douleur (QCD ou BPI 'Brief Pain Inventory'), chez les patients de chirurgie thoracique et mammaire.

Méthode Dans cette étude pilote randomisée contrôlée, 82 patients subissant une chirurgie thoracoscopique $(n=77)$ ou une mastectomie $(n=5)$ ont reçu soit un bloc continu $d u$ plan des muscles érecteurs du rachis avec de la ropivacaïne (groupe ropivacaïne), ou la même intervention avec une solution saline à $0,9 \%$ (groupe salin). Tous les patients ont reçu un bloc intercostal chirurgical (chirurgie thoracique) ou une infiltration d'anesthésique local (chirurgie mammaire). La faisabilité a été évaluée par les critères de recrutement (trois patients par semaine), de la rétention du cathéter (plus de $90 \%$ à $24 \mathrm{~h}$ ), et du taux d'attrition des patients (moins de $10 \%$ ). Les critères d'évaluation secondaires comportaient la QoR-15, le QCD et la consommation d'opioïles.

Résultats Le taux de recrutement était de 1,8 patients par semaine. Les cathéters sont restés en place chez 77 patients (94\%) à 24 h. À trois mois, cinq patients ont été perdus au suivi (6\%). Après 24 h, par rapport aux valeurs de base, le groupe ropivacaïne présentait un déclin plus léger du score de QoR-15 (différence médiane, 14; intervalle de confiance [IC] $95 \%, 2$ à 26; $P=0,02$ ) ainsi qu'une augmentation moindre du score global de QCD (différence médiane, 14; IC $95 \%, 0$ à 24; $P=0,048$ ). Aucune différence n'a été observée en matière de consommation d'opioïles $(P=$ $0,08)$.

Conclusion Dans cette étude pilote, le taux de recrutement cible n'a pas été atteint, mais les taux de rétention des cathéters et d'attrition des patients étaient tous deux satisfaisants. Une étude définitive de la QoR-15 en tant que critère d'évaluation principal nécessiterait le recrutement de 300 participants.

Enregistrement de l'étude Australian New Zealand Clinical Trials Registry (ID12618000701224); enregistrée le 30 avril 2018.

Keywords Pilot study - erector spinae plane block · patient-centred outcomes $\cdot$ quality of recovery

Poorly controlled pain following surgery may lead to persistent postsurgical pain, high opioid consumption, and opioid-related morbidity. ${ }^{1}$ The erector spinae plane (ESP) block is an ultrasound-guided interfascial plane block that was first described in $2016 .^{2}$ Since then, it has been extensively utilized in truncal surgery despite limited evidence and incomplete explanation of its mechanism of action. ${ }^{3}$ Relevant studies have focused on outcomes such as pain score and opioid consumption, ${ }^{4-7}$ and few studies have collected patient-centred outcomes.

In this pilot randomized-controlled trial, we evaluated the feasibility of a definitive trial investigating the effect of continuous ESP blockade on patient-centred outcomes following thoracic and breast surgery. Feasibility as the primary outcome was evaluated on recruitment, catheter retention at $24 \mathrm{hr}$, and patient attrition at three months. As secondary outcomes, patient-centred metrics were utilized including the quality of recovery-15 (QoR-15) which is a multidimensional measure of functional recovery following surgery and anesthesia, ${ }^{8}$ and the brief pain inventory (BPI) which evaluates pain and its interference with physical and emotional functioning. ${ }^{9}$

\section{Methods}

Study design

This double-blind parallel-group, pilot randomizedcontrolled trial was conducted at St. Vincent's Hospital Melbourne, Australia and Waikato Hospital, Hamilton, New Zealand. This study was approved by the Human Research Ethics Committee of St. Vincent's Hospital Melbourne (HREC/18/SVHM/48) on 18 April 2018 and by the Health and Disability Ethics Committees New Zealand (18/CEN/82) on 1 June 2018. This trial was registered at the Australian New Zealand Clinical Trials Registry on 30 April 2018 (ID12618000701224). Written informed consent was obtained from all study participants. This study conforms to reporting standards of the Consolidated Standards of Reporting Trials, its extension for trials addressing patient-reported outcomes, and its extension for pilot and feasibility trials. ${ }^{10-12}$

Study population

Inclusion criteria included age $\geq 18 \mathrm{yr}$, body mass index (BMI) $\quad 18-50 \quad \mathrm{~kg} \cdot \mathrm{m}^{-2}$, American Society of Anesthesiologists physical status classification I-IV, and scheduled for unilateral video-assisted thoracoscopic surgery or mastectomy. Exclusion criteria included patients with the inability to understand English, impaired cognition, planned admission to the intensive care unit, alcohol or illicit drugs abuse, daily opioid use equal to or greater than $60 \mathrm{mg}$ of oral morphine equivalents, and pre-existing neuropathic pain in the torso. 
Study intervention, randomization, and blinding

The randomization schedule was computer-generated by Stata version 15.1 (StataCorp, College Station, TX, USA) in 1:1 permuted blocks of four. Personnel not involved in the trial prepared study group assignments and stored them in the pharmacy department at St. Vincent's Hospital or in sealed opaque envelopes prepared externally at Waikato Hospital. Personnel not involved in the trial or patient care prepared identical syringes for block performance and infusion bags containing ropivacaine or saline. Participants were randomly allocated to receive either a preoperative ESP block with $30 \mathrm{~mL}$ of $0.375 \%$ ropivacaine (ropivacaine group) followed by a catheter insertion, or the same procedure but injection with $30 \mathrm{~mL}$ of $0.9 \%$ saline (saline group). Postoperatively, participants in the ropivacaine group received $20 \mathrm{~mL}$ boluses of $0.2 \%$ ropivacaine every four hours via catheter with a background infusion of 1 $\mathrm{mL} \cdot \mathrm{hr}^{-1}$. Participants in the saline group received an identical regimen with $0.9 \%$ saline. Study participants, healthcare providers, and research personnel were all blinded to group allocation.

Erector spinae plane block procedure and perioperative care

The ESP block was performed before induction of general anesthesia. Under aseptic conditions, a linear array ultrasound transducer was placed in longitudinal orientation $2.5-3 \mathrm{~cm}$ from the midline at T5 level to image the transverse process in the sagittal plane. With the patient in the sitting position, an 18G Pajunk E-catheter ${ }^{\circledR}$ needle (Pajunk, Geisingen, Germany) was introduced in the cephalo-caudad direction. The sonographic endpoint for injection was needle contact with the T5 transverse process and the erector spinae muscle group being lifted off the transverse process by the study injectate. ${ }^{2}$ After injection of $30 \mathrm{~mL}$ of study solution, a catheter was inserted. The catheter position was verified by observing the spread of 1 $\mathrm{mL}$ of normal saline in the ESP.

Study participants received a standard anesthetic and analgesic regimen. Anxiolysis and analgesia were provided with intravenous midazolam $\left(0.02-0.05 \mathrm{mg} \cdot \mathrm{kg}^{-1}\right)$ and fentanyl $\left(0.25-0.5 \mu \mathrm{g} \cdot \mathrm{kg}^{-1}\right)$. General anesthesia was induced with fentanyl $1-2 \mu \mathrm{g} \cdot \mathrm{kg}^{-1}$ and propofol $1-2.5$ $\mathrm{mg} \cdot \mathrm{kg}^{-1}$ and maintained with sevoflurane. Choice of airway, additional intraoperative fentanyl and parecoxib $40 \mathrm{mg}$ were at the discretion of the attending anesthesiologist. The protocol did not permit the use of intravenous ketamine, lignocaine, remifentanil, clonidine, dexmedetomidine, and tramadol. Intraoperative monitoring was used as recommended by Dobson et al. ${ }^{13}$ Towards completion of the surgical procedure, and consistent with routine practice at the author's institutions, surgeons performed a single-injection intercostal block to cover incisions on corresponding dermatomes for video-assisted thoracoscopic surgery and subcutaneous local anesthetic infiltration for breast surgery, using $30 \mathrm{~mL}$ of $0.375 \%$ ropivacaine. Minimum time separation of $1.5 \mathrm{hr}$ between local anesthetic dosage was ensured to minimize the risk of systemic toxicity.

In the postanesthesia care unit (PACU), fentanyl $20 \mu \mathrm{g}$ was titrated every five minutes to achieve pain score by numerical rating scale (NRS) (0-10: 0, no pain; 10, worst imaginable pain) of $<3$. Postoperative analgesia comprised oral paracetamol 1,000 mg every six hours and ibuprofen $400 \mathrm{mg}$ every eight hours (in the absence of contraindications). All patients received a fentanyl patient-controlled analgesia (PCA) device with a $20 \mu \mathrm{g}$ bolus and a five-minutes lock-out, for $24 \mathrm{hr}$. A ketamine infusion was added when the pain score was $\geq 7$ despite the use of a PCA device. Boluses of ropivacaine or saline were delivered through the ESP catheter by the nursing staff by programming the infusion pump every four hours to coincide with the time of nursing observation. Intermittent boluses were continued for a minimum of 24 $\mathrm{hr}$ after block performance. The total number of delivered boluses and missed scheduled boluses were recorded.

Feasibility and secondary outcome measures

The primary outcome of feasibility was evaluated based on recruitment (three patients per week), catheter retention (above $90 \%$ at $24 \mathrm{hr}$ ), and patient attrition (less than $10 \%$ at three months). Secondary outcomes comprised the QoR15, BPI, opioid consumption, dermatomal extent of sensory loss to cold, and patient satisfaction.

The QoR-15 is a multidimensional patient-reported instrument that has been used to assess functional recovery. ${ }^{8}$ The QoR-15 comprises five domains: pain (two questions), physical comfort (five questions), physical independence (two questions), psychological support (two questions), and emotional state (four questions). Each question uses a ten-point scale ranging from 0 (pain none of the time) to 10 (pain all of the time) with scoring reversed for negative questions. The sum of the individual domains generates the global score $(0$, worst recovery; 150 , optimal recovery). A change in the score of 8 or more signifies a clinically important improvement or deterioration. ${ }^{14}$ The QoR-15 questionnaire was administered preoperatively and $24 \mathrm{hr}$ after block performance. The variance of QoR-15 was used to inform future sample size calculation.

The BPI instrument assesses two domains: pain and pain-related interference with physical and emotional functioning. ${ }^{9}$ The pain subscales of the BPI include 
assessment of "worst", "least", "average" and "current" level of pain in the last $24 \mathrm{hr}$. Pain-related interference with physical and emotional functioning is evaluated with seven questions using an 11-point Likert scale ( 0 , no interference; 10 complete interference in general activity, mood, walking ability, normal work, relations with other people, sleep, and enjoyment of life). A further question on relief provided by pain treatments is calculated as follows: percentage pain relief divided by 10 and then subtracted from 10 ( 0 , complete relief; 10 , no relief). The sum of the above domains derives the global score of the BPI $(0$, optimal; 120, worst possible). The BPI questionnaire was administered preoperatively, $24 \mathrm{hr}$ after block performance and at three months postoperatively.

Opioid consumption (reported in oral morphine equivalents) was captured at four time periods: intraoperatively, in the PACU, from PACU discharge until $24 \mathrm{hr}$ after block performance, and between 24 and $48 \mathrm{hr}$ after block performance. Oral morphine equivalents (mg) were calculated using the following conversion: oral morphine $(\mathrm{mg})$ equates to intravenous fentanyl $(\mu \mathrm{g})$ x 0.2 , intravenous morphine $(\mathrm{mg})$ x 3 , oral oxycodone $(\mathrm{mg}) \times 1.5$, tramadol $(\mathrm{mg}) \times 0.2$, and tapentadol $(\mathrm{mg}) \times$ $0.4 .^{15}$

Dermatomal sensory loss to cold was assessed by applying ice to the anterior (midclavicular), lateral (midaxillary) and posterior (midscapular) sections of the torso (T1-T12) in the PACU and $24 \mathrm{hr}$ after the ESP block was performed. The total number of blocked dermatomal segments was recorded.

Patient satisfaction was evaluated postoperatively using a questionnaire that addressed the following domains: provision of information, interaction with the anesthesiologist performing the procedure, and willingness to have the same procedure repeated in the future. ${ }^{16}$ Provision of information by and interaction with the anesthesiologist was evaluated using a five-point scale ("completely dissatisfied", "dissatisfied", "neither satisfied or dissatisfied", "satisfied" and "completely satisfied"). Willingness to have the same procedure again was evaluated using a binary scale (yes or no). Hospital length of stay in number of days was also recorded.

\section{Statistical analysis}

Sample size was based on the secondary QoR-15 outcome where we determined that 64 patients ( 32 per group) were required to detect a difference of 15 in QoR-15 scores with $80 \%$ power (alpha $=0.05$ ) assuming a standard deviation of $21 .{ }^{17}$ We anticipated that we would be able to recruit more than 40 patients per arm within a year, therefore we aimed to recruit 82 patients in total to better assess the feasibility outcomes.
Continuous or discrete baseline characteristics were described using median [interquartile range (IQR)] or mean (standard deviation $[\mathrm{SD}]$ ) as appropriate. Categorical data were summarized with frequencies and proportions. We assessed the effect of ESP block on all continuous and discrete outcome measures using the Wilcoxon rank-sum test and reported the Hodges-Lehmann estimate and 95\% confidence interval (CI). The two-sample HodgesLehmann estimate of the median difference is the median of all $(n 1 \times n 2)$ pairwise differences between observations in the two study groups, where $n 1$ and $n 2$ are the two respective sample sizes. The median difference results were reported as saline minus ropivacaine groups $(95 \%$ CI). Robust $95 \%$ CI for the median pairwise difference was estimated using the "cendif" program in Stata version 14. For all analyses, $P<0.05$ was considered statistically significant. Intention-to-treat analysis was applied for all patients who received study intervention. The sample size calculation and analyses were performed using Stata version 14.1 (StataCorp, College Station, TX, USA).

\section{Results}

From 4 June 2018 to 23 April 2019, 225 patients were assessed for eligibility and 84 patients were randomized to the study. Two patients were withdrawn prior to the study intervention. One patient with low BMI meeting the exclusion criteria was recruited because of an error in the medical record. Another patient was withdrawn because of a change in the surgical plan. Of 82 patients ( 77 thoracic surgery, five breast surgery), 42 patients received continuous ESP block with $0.2 \%$ ropivacaine (ropivacaine group) and 40 patients received catheters delivering $0.9 \%$ saline (saline group) (Fig. 1). There were no clinically important differences in patient or procedural data including baseline QoR-15 and BPI global scores between groups (Table 1).

Recruitment rate averaged 1.8 patients per week. Complete perioperative data set was obtained in all 82 patients. At $24 \mathrm{hr}$, three patients in the saline group and two patients in the ropivacaine group did not have functional catheters in situ (catheter retention rate 94\%, Fig. 1). One catheter was dislodged because of dyskinesia related to Parkinson's disease. In four patients, catheters were removed prior to 24-hr follow-up because of discomfort or swelling around the catheter site, caused by boluses of solution. These patients did not show signs of hematoma or infection, and symptoms resolved rapidly following catheter removal. Postoperatively, a median [IQR] of 10 [6-12] boluses were delivered in the saline group and 11 [10-13] in the ropivacaine group (median difference, -1 ; $95 \% \mathrm{CI},-5$ to $0 ; P=0.05)$. Seventy-one out of $82(87 \%)$ 


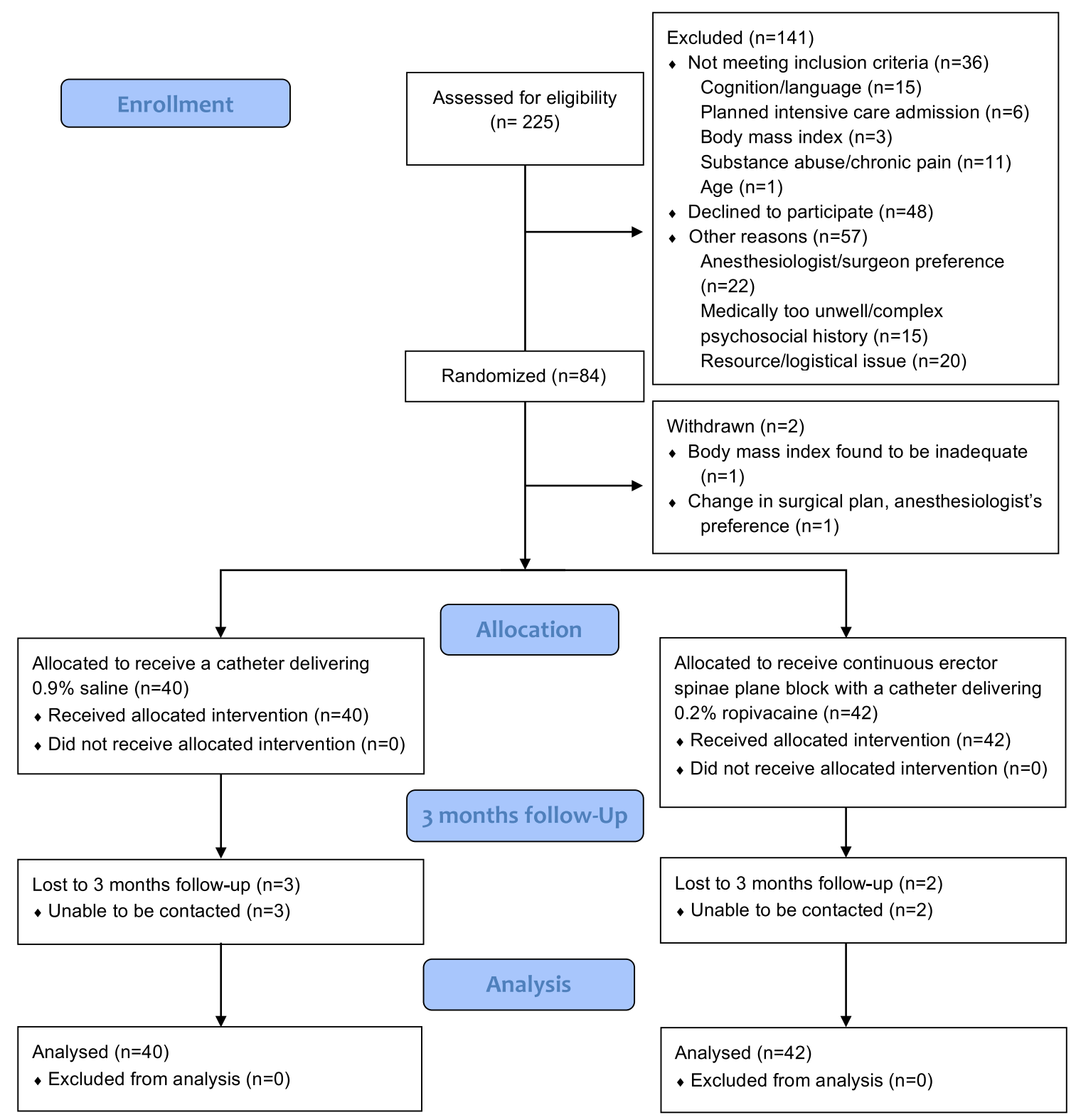

Fig. 1 Consolidated Standards of Reporting Trial diagram of the study. All 82 patients who received the study intervention were analyzed with complete perioperative data set.

patients received all scheduled boluses while catheters were in situ. Of the remaining 11 patients (six in the saline group and five in the ropivacaine group), eight patients missed one scheduled bolus and three patients missed more than one scheduled bolus. Five patients $(6 \%)$ were lost to follow-up when we performed the BPI questionnaires at three months (Fig. 1).

The secondary outcomes are summarized in Table 2. The median [IQR] 24-hr QoR-15 global scores were 97 [77-123] in the saline group and 103 [92-122] in the ropivacaine group (median difference, -7 ; $95 \% \mathrm{CI},-20$ to 5 ; $P=0.22$ ). Compared with baseline values, the $24-\mathrm{hr}$ QoR15 global score declined by $37.5[12.5-54]$ in the saline group compared with 20 [7-33] in the ropivacaine group (median difference, $14 ; 95 \% \mathrm{CI}, 2$ to $26 ; P=0.02$; Table 2, Fig. 2).

The median [IQR] 24-hr BPI global scores were 53 [3572] in the saline group and 41 [22-58] in the ropivacaine group (median difference, $7 ; 95 \% \mathrm{CI},-2$ to $20 ; P=0.12$ ). Compared with baseline values, the 24-hr BPI global score increased by 39 [25-55] in the saline group compared with 22 [11-44] in the ropivacaine group (median difference, $14 ; 95 \%$ CI, 0 to $24 ; P=0.048$, Table 2). The median [IQR] NRS pain scores reported by the patient as the average over the previous $24 \mathrm{hr}$ were 4 [2-6] in the saline group and $3[2-4]$ in the ropivacaine group (median 
Table 1 Patient and procedural characteristics

\begin{tabular}{lll}
\hline & Saline group $(n=40)$ & Ropivacaine group $(n=42)$ \\
\hline Age $(\mathrm{yr})$ & $62.6(13.3)$ & $63.9(13.7)$ \\
Weight $(\mathrm{kg})$ & $80.6(17.7)$ & $79.5(15.1)$ \\
Height $(\mathrm{cm})$ & $169(9)$ & $169(11)$ \\
BMI $\left(\mathrm{kg} \cdot \mathrm{m}^{2}\right)$ & $28.1(5.5)$ & $27.8(5.1)$ \\
Diabetes, \% & $1(2)$ & $7(17)$ \\
ASA physical status III, \% & $30(75)$ & $31(74)$ \\
Regular opioid use, \% & $3(7)$ & $3(8)$ \\
Baseline brief pain Inventory global score & $3[0-30]$ & $5[0-36]$ \\
Baseline quality of recovery-15 global score & $135[126-143]$ & $133[119-141]$ \\
Thoracic surgery, \% & & $14(33)$ \\
Video-assisted lobectomy & $17(43)$ & $16(38)$ \\
Video-assisted wedge resection/segmentectomy & $12(30)$ & $9(21)$ \\
Other video-assisted thoracic surgery or other & $9(23)$ & $3(7)$ \\
Breast surgery, $\%$ & $2(5)$ & $26(65)$ \\
Cancer surgery, \% & $32(76)$ & $146[100-200]$ \\
Surgical duration (min) & $156[83-205]$ & \\
\hline
\end{tabular}

Data presented as $n(\%)$, mean (standard deviation) or median [interquartile range]

ASA $=$ American Society of Anesthesiologists; BMI = body mass index

difference, $1 ; 95 \% \mathrm{CI}, 0$ to $2 ; P=0.02$ ). The pain subscale of BPI is presented in Table 2 and Fig. 3.

There was no statistically significant difference in opioid consumption between groups in the first $24 \mathrm{hr}$ (median difference, $36 \mathrm{mg}$ oral morphine equivalents; $95 \% \mathrm{CI},-5$ to $78 \mathrm{mg} ; P=0.08$ ), and in the $24-48 \mathrm{hr}$ period (median difference, $3.4 \mathrm{mg}$ oral morphine equivalents; $95 \% \mathrm{CI}$, -15 to $26 ; P=0.64$, Table 2). Parecoxib was used in 29 out of 40 patients $(72.5 \%)$ in the saline group and 28 out of 42 patients $(66.7 \%)$ in the ropivacaine group $(P=0.64)$. One patient in the ropivacaine group and three patients in the saline group had severe pain requiring ketamine infusion.

The ropivacaine group had significantly higher proportions of dermatomal segments with sensory loss to cold than the saline group did both in the PACU (ropivacaine: 12 [4-17], saline: 5 [0-12]; median difference, $-4 ; 95 \% \mathrm{CI},-9$ to $0 ; P=0.02$ ) and $24 \mathrm{hr}$ after block performance (ropivacaine: 5 [0-10], saline: 0 [0-3]; median difference, $-3 ; 95 \% \mathrm{CI},-6$ to $0 ; P<0.001$, Table 2).

Patients were satisfied with the explanation (96\%) and information (97\%) about the study intervention. Ninetynine percent of patients also responded they were satisfied with their interactions with anesthesiologists. Ninety percent (saline group) and $100 \%$ (ropivacaine group) of patients were willing to have another ESP block in future surgery.

Hospital length of stay was 3 [2-6] days in the saline group and $4[3-6]$ days in the ropivacaine group $(P=0.13)$.
At three months postoperatively, the median of BPI global score was 0 in both groups $(P=0.72$, Table 2 , Fig. 3$)$. Ten patients required opioid at three months (six in the saline group, four in the ropivacaine group) with seven patients taking oxycodone and three taking weak opioid (tramadol or tapentadol).

Based on the variance in our data, for an alpha of 0.05 and a power of 0.9 , approximately 300 study participants in total would be needed to detect a minimally clinical important difference of 8 in the QoR-15 global score as the primary outcome. ${ }^{14}$

\section{Discussion}

In this pilot randomized-controlled trial evaluating feasibility, we did not achieve our target recruitment rate. Forty-eight eligible patients ( $21 \%$ of all eligible patients) declined to participate in the study and 22 patients (10\%) were not recruited according to the anesthesiologist's and surgeon's preferences. Possible reasons for our recruitment rate being below our target were the psychological burden of asking a patient recently diagnosed with cancer to participate in a trial, and the unknown analgesic efficacy of the ESP block. Nevertheless, because we did not specifically collect such data, we cannot comment on the reasons other than those reported in the CONSORT diagram. The most effective way to improve recruitment rate to more than three patients per week in a future 
Table 2 Main outcomes comparing the two groups

\begin{tabular}{|c|c|c|c|c|}
\hline & $\begin{array}{l}\text { Saline group } \\
(n=40)\end{array}$ & $\begin{array}{l}\text { Ropivacaine group } \\
(n=42)\end{array}$ & $\begin{array}{l}\text { Median difference } \\
\text { ( } 95 \% \text { confidence interval) }\end{array}$ & $P$ value \\
\hline \multirow{2}{*}{\multicolumn{5}{|c|}{$\begin{array}{l}\text { Quality of recovery-15 ( } 24 \mathrm{hr}) \\
\text { subdomain }\end{array}$}} \\
\hline & & & & \\
\hline Pain & $13[10-16]$ & $14[10-17]$ & $-1(-3$ to 1$)$ & 0.22 \\
\hline Physical comfort & $32[24-40]$ & 32 [26-39] & $-1(-6$ to 4$)$ & 0.76 \\
\hline Physical independence & $9[0-13]$ & 10 [3-14] & $-2(-6$ to 0$)$ & 0.07 \\
\hline Psychological support & $19[17.5-20]$ & $20[18-20]$ & $0(-1$ to 0$)$ & 0.36 \\
\hline Emotions & $30[21-36]$ & $33.5[25-38]$ & $-2(-6$ to 1$)$ & 0.19 \\
\hline Global score & 97 [77-123] & $103[92-122]$ & $-7(-20$ to 5$)$ & 0.22 \\
\hline Change from baseline score & $38[13-54]$ & $20[7-33]$ & $14(2$ to 26$)$ & 0.02 \\
\hline \multicolumn{5}{|l|}{ Brief pain inventory ( $24 \mathrm{hr}$ ) } \\
\hline \multicolumn{5}{|l|}{ Numeric rating scale } \\
\hline Average pain & $4[2-5.5]$ & $3[2-4]$ & $1(0$ to 2$)$ & 0.018 \\
\hline Least pain & $2[1-3]$ & $2[0-2]$ & $0(0$ to 1$)$ & 0.22 \\
\hline Worst pain & $7[5-9]$ & $7[3-8]$ & $1(-1$ to 2$)$ & 0.28 \\
\hline Current pain & $3[0-4]$ & $2[1-3]$ & $0(-1$ to 1$)$ & 0.60 \\
\hline Pain subscale & $15[9-21]$ & $14[8-18]$ & $2(0$ to 6$)$ & 0.09 \\
\hline Interference subscale & $35[21-44]$ & $26[14-38]$ & $5(-3$ to 14$)$ & 0.24 \\
\hline Percentage of relief & $80[60-90]$ & $80[70-90]$ & $0(-10$ to 0$)$ & 0.25 \\
\hline Global score & $53[35-72]$ & $41[22-58]$ & $7(-2$ to 20$)$ & 0.12 \\
\hline Change from baseline score & $39[25-55]$ & $22[11-44]$ & $14(0$ to 24$)$ & 0.048 \\
\hline \multicolumn{5}{|l|}{ Brief pain inventory (3 months) } \\
\hline Pain subscale & $0[0-11]$ & $0[0-8]$ & $0(0$ to 0$)$ & 0.53 \\
\hline Interference subscale & $0[0-15]$ & $0[0-7]$ & $0(0$ to 0$)$ & 0.45 \\
\hline Percentage of relief & $100[85-100]$ & $100[100-100]$ & $0(0$ to 0$)$ & 0.66 \\
\hline Global score & $0[0-34]$ & $0[0-17]$ & $0(0$ to 0$)$ & 0.72 \\
\hline \multicolumn{5}{|c|}{ Opioid consumption in oral morphine equivalents (mg) } \\
\hline Intraoperative & $70[58-90]$ & $80[50-90]$ & $0(-10$ to 10$)$ & 0.79 \\
\hline PACU & $12[0-22]$ & $7[0-20]$ & $0(0$ to 9$)$ & 0.35 \\
\hline First $24 \mathrm{hr} *$ & $128[94-212]$ & $100[56-156]$ & $36(-5$ to 78$)$ & 0.08 \\
\hline $24-48 \mathrm{hr} \dagger$ & $45[15-119]$ & 39 [15-93] & $3.4(-15$ to 26$)$ & 0.64 \\
\hline \multicolumn{5}{|l|}{ Sensory block } \\
\hline PACU: number of blocked dermatomes & $5[0-12]$ & $12[4-17]$ & $-4(-9$ to 0$)$ & 0.02 \\
\hline $24 \mathrm{hr}$ : number of blocked dermatomes & $0[0-3]$ & $5[0-10]$ & $-3(-6$ to 0$)$ & $<0.001$ \\
\hline
\end{tabular}

Data presented as median [interquartile range]. *From PACU discharge until $24 \mathrm{hr}$ after block performance. $†$ Between 24 and $48 \mathrm{hr}$ after block performance.

PACU $=$ postanesthesia care unit.

definitive trial will be to increase the number of recruiting sites. Both catheter retention rate at $24 \mathrm{hr}$ and patient attrition at three months met our feasibility criteria.

Our results suggest that ESP block might improve patient-centred outcomes. The ropivacaine group had a higher 24-hr QoR-15 score with median difference of 7 between groups, which is close to a clinically important difference. ${ }^{14}$ At $24 \mathrm{hr}$, the changes in both QoR-15 and BPI global scores from baseline indicate an improved outcome for patients in the ropivacaine group. Continuous
ESP block reduced the pain score reported by patients as the average over previous $24 \mathrm{hr}$ by one compared with a catheter delivering $0.9 \%$ saline. This indicates that ESP block incrementally improves pain score even with concurrent local anesthetic administration by the surgeon. In accordance with these findings, we have observed more enhanced sensory blockade in the ropivacaine group both in the PACU and at $24 \mathrm{hr}$, supporting potential efficacy of the ESP block and the need to perform a definitive trial. 

baseline and $24 \mathrm{hr}$ after block performance, comparing two improved quality of recovery) The data are presented as the median, interquartile range (boxes), adjacent values (whiskers) and outside values (dots).
Fig. 2 Boxplots of quality of recovery-15 global scores at groups (higher score indicates

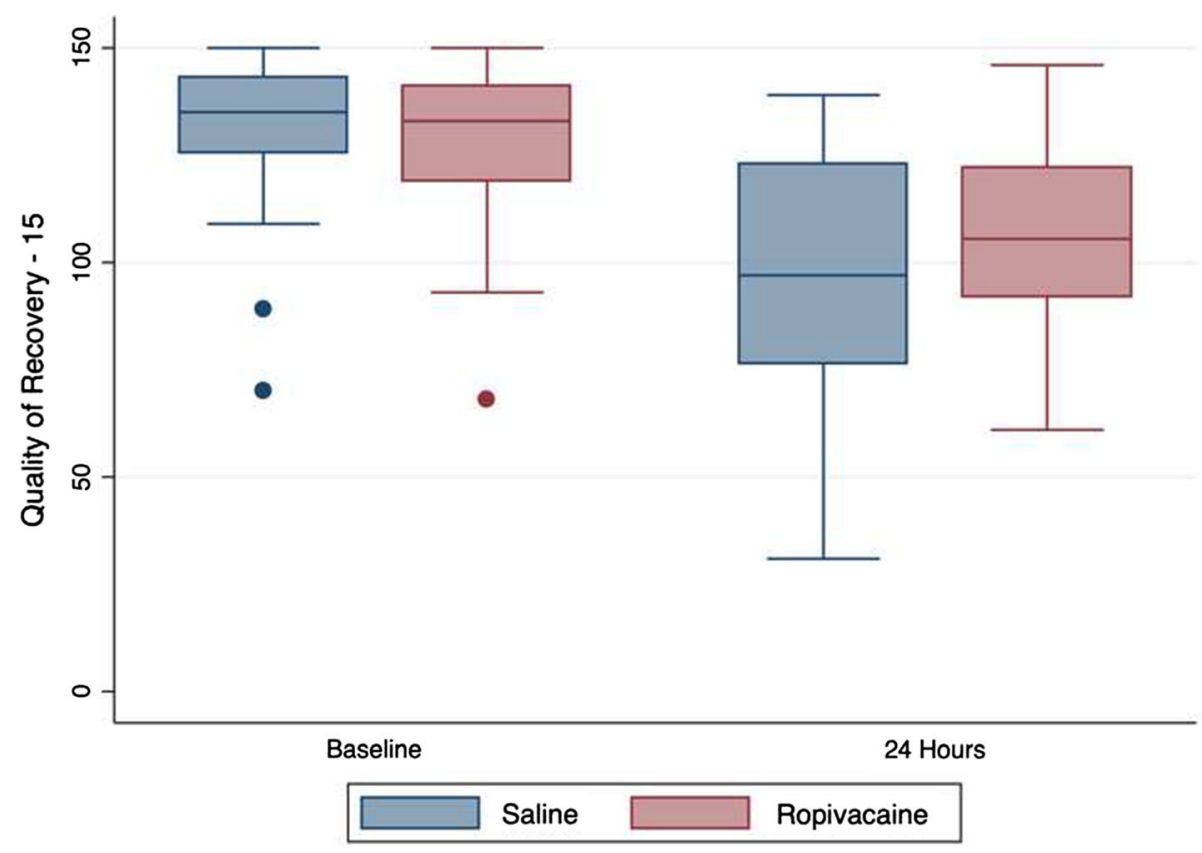

Fig. 3 Boxplots of brief pain inventory global scores with pain and interference subscales $24 \mathrm{hr}$ after block performance and at three months postoperatively, comparing two groups (lower score indicates less dysfunction). The data are presented as the median, interquartile range (boxes), adjacent values (whiskers) and outside values (dots).

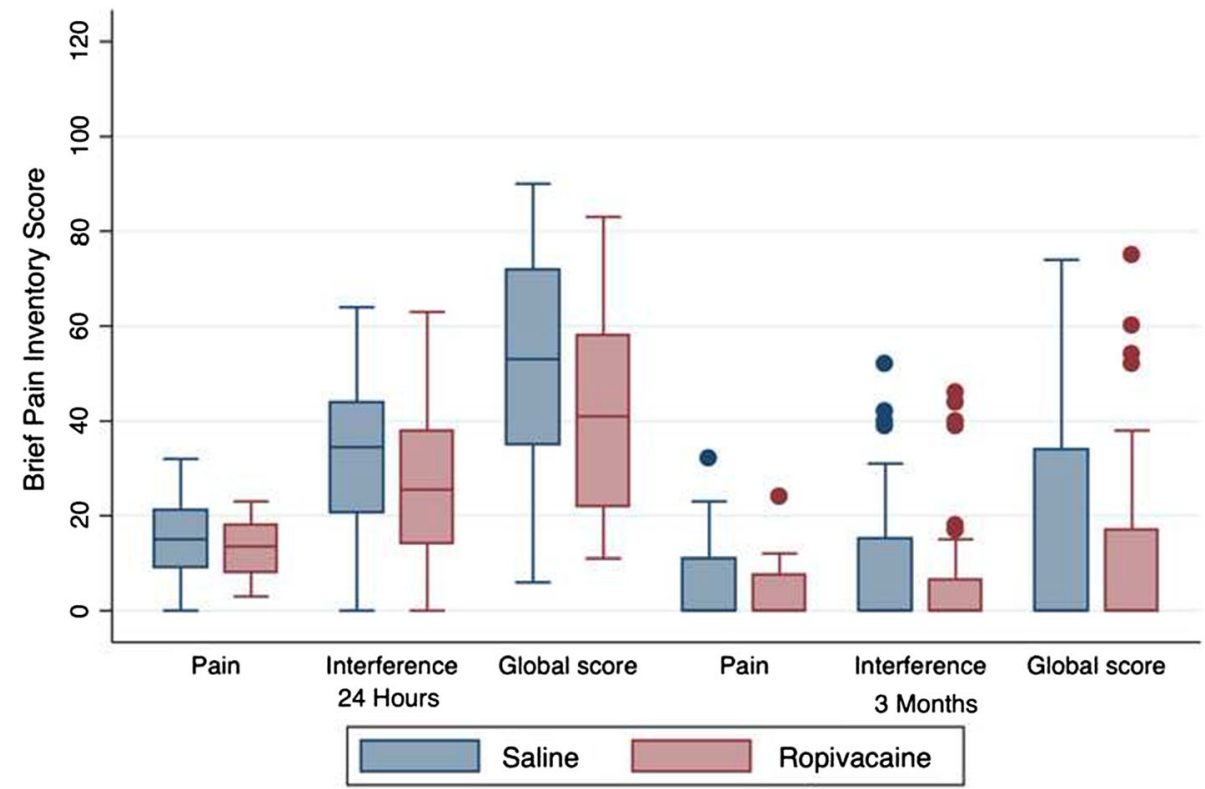

In a recent randomized-controlled trial, Ciftci et al. showed that addition of preoperative single-injection ESP block reduced opioid consumption and pain scores following video-assisted thoracic surgery. ${ }^{4}$ Nevertheless, this study was unblinded, so the findings may be at risk of bias. Other published studies on video-assisted thoracoscopic surgery have compared the ESP block with other regional anesthetic techniques. In a prospective randomized non-inferiority trial, Taketa et al. showed that the analgesic efficacy of continuous ESP block was non-inferior to continuous paravertebral block following video-assisted thoracic surgery in terms of pain scores at 24 hr. ${ }^{18}$ In contrast, Chen et al. found that single-injection ESP block was inferior to multiple-injection paravertebral block in reducing pain scores and opioid consumption in thoracoscopic surgery. They also found that there were no differences in pain scores and opioid consumption between ESP block and interscostal nerve block groups. ${ }^{19}$ Because we used two regional anesthetic techniques in our study (ESP block and local anesthetic administration by surgeons) it is difficult to make a direct comparison between the studies by Ciftci, Taketa, and Chen with our 
study. In summary, the efficacy of the ESP block is inconclusive in this study cohort, indicating the need for further studies.

Future trials on the ESP block should focus on meaningful patient-centred outcomes to determine its efficacy from the patient's perspective. ${ }^{20}$ In accordance with our results, Yao et al. showed that ESP block improved QoR in patients undergoing modified radical mastectomy, compared with injection with $0.9 \%$ saline in a sample size of 82 patients. ${ }^{21}$ Nevertheless, Yao et al. report an interquartile range of 6 for QoR-15 global score, which indicates reduced variance compared with that collected from a similar surgical cohort. Based on variance in our data, a definitive trial evaluating the efficacy of the ESP block will require approximately 300 research participants for QoR-15 as the primary outcome.

This study has limitations. Resources and logistical issues resulted in loss of eligible patients, which introduced potential selection bias. This feasibility study was performed on video-assisted thoracoscopic surgery and mastectomy, and the results are not generalizable to other types of surgery. In addition, we recruited only five patients undergoing mastectomy, so it is difficult to comment on the effectiveness of the ESP block in this study cohort.

When interpreting the results of this current study, readers should take into account that local anesthetic used by the surgeon may have masked the full benefit of the ESP block. Nevertheless, we regard it the best practice not to disadvantage the control group by not using any regional anesthetic techniques. In the immediate postoperative period, QoR-15 and BPI questionnaires were not implemented beyond $24 \mathrm{hr}$. Finally, the optimal regimen and mode of delivery of continuous ESP block is currently unknown.

\section{Conclusions}

In this pilot randomized-controlled trial, we did not achieve our target recruitment rate. The catheter retention rate at 24 $\mathrm{hr}$ and patient attrition at three months were both satisfactory. This study showed that an ESP block may potentially improve patient-centred outcomes including QoR-15 and BPI. To confirm these findings, a randomizedcontrolled trial with approximately 300 participants is required.

Acknowledgements The authors thank thoracic surgeons Dr. Gavin M Wright, Dr. Naveed Alam (Department of Cardiothoracic Surgery, St. Vincent's Hospital Melbourne, Australia), Dr. Paul Conaglen and Dr. Felicity Meikle (Waikato Cardiothoracic Unit, Waikato Hospital, Hamilton, New Zealand) for supporting the study. Jonathan Termaat and Gay Mans (Department of Anesthesia, Waikato Hospital, Hamilton, New Zealand) provided substantial support to ensure smooth-running of the study protocol. Tara Menichelli (Department of Pharmacy, St. Vincent's Hospital Melbourne, Australia) assisted with preparation of study syringes and infusion bags, and Dr. Seamus O'Flaherty (Department of Anesthesia and Acute Pain Medicine, St. Vincent's Hospital Melbourne, Australia) assisted with postoperative follow-up.

Author contributions Yoshiaki Uda, Kelly Byrne, Anjalee Brahmbhatt, Robert Gotmaker, and Michael J. Barrington contributed to the conception and design of the study; protocol execution; acquisition, analysis, and interpretation of data; and drafting the article. Daniel Lim contributed to the conception and design of the study, and protocol execution. Yasutaka Konishi and Tessa Eves contributed to the conception and design of the study and acquisition of data. Emma Paxton contributed to the acquisition of data.

\section{Disclosures None.}

Funding statement This study was funded by the Australian and New Zealand College of Anaesthetists, Project Grant 19/032 and an unrestricted grant from the Waikato Medical Research Foundation.

Editorial responsibility This submission was handled by Dr. Hilary P. Grocott, Editor-in-Chief, Canadian Journal of Anesthesia.

\section{References}

1. Kharasch ED, Brunt LM. Perioperative opioids and public health. Anesthesiology 2016; 124: 960-5.

2. Forero M, Adhikary SD, Lopez H, Tsui C, Chin KJ. The erector spinae plane block: a novel analgesic technique in thoracic neuropathic pain. Reg Anesth Pain Med 2016; 41: 621-7.

3. Tsui BC, Fonseca A, Munshey F, McFadyen G, Caruso TJ. The erector spinae plane (ESP) block: a pooled review of 242 cases. J Clin Anesth 2019; 53: 29-34.

4. Ciftci B, Ekinci M, Celik EC, Tukac IC, Bayrak Y, Atalay YO. Efficacy of an ultrasound-guided erector spinae plane block for postoperative analgesia management after video-assisted thoracic surgery: a prospective randomized study. J Cardiothorac Vasc Anesth 2020; 34: 444-9.

5. Abu Elyazed MM, Mostafa SF, Abdelghany MS, Eid GM. Ultrasound-guided erector spinae plane block in patients undergoing open epigastric hernia repair: a prospective randomized controlled study. Anesth Analg 2019; 129: 235-40.

6. Gurkan Y, Aksu C, Kus A, Yorukoglu UH, Kilic CT. Ultrasound guided erector spinae plane block reduces postoperative opioid consumption following breast surgery: a randomized controlled study. J Clin Anesth 2018; 50: 65-8.

7. Hamed MA, Goda AS, Basiony MM, Fargaly OS, Abdelhady $M A$. Erector spinae plane block for postoperative analgesia in patients undergoing total abdominal hysterectomy: a randomized controlled study original study. J Pain Res 2019; 12: 1393-8.

8. Stark PA, Myles PS, Burke JA. Development and psychometric evaluation of a postoperative quality of recovery score: the QoR15. Anesthesiology 2013; 118: 1332-40.

9. Cleeland CS, Ryan KM. Pain assessment: global use of the brief pain inventory. Ann Acad Med Singapore 1994; 23: 129-38.

10. Schulz KF, Altman DG, Moher D, CONSORT Group. CONSORT 2010 statement: updated guidelines for reporting parallel group randomised trials. BMJ 2010; 340: c332. 
11. Calvert M, Blazeby J, Altman DG, et al. Reporting of patientreported outcomes in randomized trials: the CONSORT PRO extension. JAMA 2013; 309: 814-22.

12. Eldridge SM, Chan CL, Campbell MJ, et al. CONSORT 2010 statement: extension to randomised pilot and feasibility trials. Pilot Feasibility Stud 2016; 355: i5239.

13. Dobson G, Chow L, Flexman A, et al. Guidelines to the practice of anesthesia - revised edition 2019. Can J Anesth 2019; 66: 75108.

14. Myles PS, Myles DB, Galagher W, Chew C, MacDonald N, Dennis A. Minimal clinically important difference for three quality of recovery scales. Anesthesiology 2016; 125: 39-45.

15. Nielsen S, Degenhardt L, Hoban B, Gisev N. A synthesis of oral morphine equivalents (OME) for opioid utilisation studies. Pharmacoepidemiol Drug Saf 2016; 25: 733-7.

16. Ironfield CM, Barrington MJ, Kluger R, Sites B. Are patients satisfied after peripheral nerve blockade? Results from an international registry of regional anesthesia. Reg Anesth Pain Med 2014; 39: 48-55.

17. Barrington MJ, Seah GJ, Gotmaker R, Lim D, Byrne K. Quality of recovery after breast surgery: a multicenter randomized clinical trial comparing pectoral nerves interfascial plane (pectoral nerves II) block with surgical infiltration. Anesth Analg 2020; 130: 1559-67.
18. Taketa Y, Irisawa Y, Fujitani T. Comparison of ultrasound-guided erector spinae plane block and thoracic paravertebral block for postoperative analgesia after video-assisted thoracic surgery: a randomized controlled non-inferiority clinical trial. Reg Anesth Pain Med 2020; 45: 10-15.

19. Chen $N$, Qiao $Q$, Chen $R, X u Q$, Zhang $Y$, Tian $Y$. The effect of ultrasound-guided intercostal nerve block, single-injection erector spinae plane block and multiple-injection paravertebral block on postoperative analgesia in thoracoscopic surgery: a randomized, double-blinded, clinical trial. J Clin Anesth 2020; 59: $106-11$

20. Grocott HP. Erector Spinae plane block for postoperative analgesia: a magic bullet too good to be true, or is it just too soon to tell? Anesth Analg 2020; 130: e29.

21. Yao $Y$, Li H, He $Q$, Chen $T$, Wang $Y$, Zheng $X$. Efficacy of ultrasound-guided erector spinae plane block on postoperative quality of recovery and analgesia after modified radical mastectomy: randomized controlled trial. Reg Anesth Pain Med 2020; 45: 5-9.

Publisher's Note Springer Nature remains neutral with regard to jurisdictional claims in published maps and institutional affiliations. 